\title{
ANOTAÇÕES DE ENFERMAGEM
}

\author{
Rosa Aurea Quintella Fernandes* \\ Maria Josefina Leuba Salum** \\ Marina Borges Teixeira*** \\ Regina C. Albuquerque Lemmi**** \\ Miako Miura*****
}

FERNANDES, R. A. Q.; SALUM ,M. J. L.; TEIXEIRA, M. B.; LEMMI, R. C. A.; MIURA, M. Anotações de enfermagem. Rev. Esc. Enf. USP, São Paulo, 15(1): 63-68, 1981.

As autoras sugerem normas gerais para o procedimento das anotações de enfermagem, visando a homogeneizar o ensino e a facilitar a sedimentação do aprendizado dos alunos de enfermagem.

\section{INTRODUÇÃO}

Os docentes da Escola de Enfermagem da USP vinham, há algum tempo, sentindo que não havia um princípio comum na orientação dada aos alunos no que tange às anotações de enfermagem: cada disciplina tinha exigências diferentes em vários aspectos. Esse fato era confirmado na prática, pois os alunos queixavam-se de que as orientações sobre "como" e "o que anotar" mudavam em cada estágio do curso, o que realmente dificultava a sedimentação do aprendizado.

Em vista disso, a Comissão de Graduação da Escola criou uma subcomissão para sugerir normas gerais de procedimento d'as anotações, buscando assim a homogeneização do ensino e das exigências referentes a elas.

Os elementos da subcomissão são docentes de diferentes disciplinas da Escola. $\mathrm{Na}$ sua constituição houve a preocupação de incluir docentes de disciplinas ministradas no tronco profissional comum.

Para selecionar os itens fundamentais que deveriam estar incluídos nas anotações de enfermagem, foi levado em consideração o que há de comum no que vem sendo solicitado do estudante durante o curso. Foi também considerada a orientação que vinha sendo dada a enfermeiros, auxiliares de enfermagem e atendentes pelo Serviço de Formação, Atualização e Aperfeiçoamento de Pessoal do Hospital das Clínicas da Faculdade de Medicina da USP, ouvidas a diretora desse Serviço e a chefe de uma de suas seções. Nessas coletas de dado, foi verificado a diversidade de conduta entre as diversas disciplinas, bem como a dissociação entre as exigências teóricas e práticas. Foi identificado que, ou o ensino é

* Professor Assistente da disciplina Introdução à Enfermagem e Fundamentos de Enfermagem da EEUSP. Mestre em Enfermagem.

* * Professor Assistente da disciplina Nutrição e Dietética Aplicadas à Enfermagem da EEUSP. Mestre em Enfermagem.

*** Professor Assistente da disciplina Enfermagem Psiquiktrica da EEUSP. Mestre em Enfermagem.

**** Auxiliar de Ensino da disciplina Administração Aplicada à Enfermagem da EEUSP.

**** Auxiliar de Ensino da disciplina Enfermagem Médico-Círúrgica I da EEUSP. 
por demais elitizado, ou ainda não foi alcançado o entrosamento desejado entre escola e campo de trabalho. Nesse sentido, o grupo verificou que, obviamente, a interação entre ambos é fundamental para que se cristalize uma prática dc enfermagem adequada e fundamentada na realidade.

Embora haja entre os profissionais de enfermagem consenso de que a anotação é um instrumento extremamente valioso, isso não tem sido devidamente valorizado.

Deve-se deixar bem claro que a anotação é um instrumento valorativo de grande significado na assistência de enfermagem e na sua continuidade, tornando-se pois indispensável na aplicação do processo de enfermagem.

DUARTE et alii (1976) afirmam que "a assistência de enfermagem somente se fará plena de autonomia, quando a ela for considerado de forma irrestrita o planejar, o prescrever de cuidados e a anotação desses quando prestados".

Assim, a anotação do cuidado prestado deve ser um meio para controlar e avaliar a assistência de enfermagem. É necessário, ainda, considerar o valor das anotações como fonte de investigação, como instrumento de educação e como documento legal (ANGERAMI, 1976; OGUISSO, 1975).

RIBEIRO (1972), analisando os resultados obtidos em um levantamento de prontuários hospitalares, verificou que apenas $0,5 \%$ das anotações neles existentes eram feitas por enfermeiros e que as informações transcritas não revelavam qualidade: "não têm seqüência, não quantificam nada, não objetivam a situação do paciente, enfim não revelam planejamento dos cuidados para atender às necessidades de cada paciente em particular". Assim, parece imperioso que a importância das anotações seja considerada durante todo o curso de graduação, o que implica na exigência do aperfeiçoamento constante da orientação das anotações feitas pelos estudantes. É necessário, porém, orientação no que se refere ao conteúdo e à forma das anotações.

A tentativa de padronizar o ensino das anotações visava não só a uniformizar as solicitações pelas diversas disciplinas desta Escola, como também a estender tal padronização, a longo prazo, na prática diária da assistência de Enfermagem nas diversas instituições hospitalares.

Os tópicos sobre anotação aqui discutidos constituem itens essenciais que sugerimos sejam considerados na orientação do aluno em todas as disciplinas e são o resultado do trabalho realizado pela sub-comissão.

\section{NORMAS PARA AS ANOTAÇÕES DE ENFERMAGEM}

Foram estabelecidas normas de caráter geral e normas especificas que facilitassem a operacionalização em relação a "o que anotar" e a "como anotar". A fim de facilitar a compreensão dessas normas, é necessário tecer, inicialmente, algumas considerações, para, em seguida, descrever o conteúdo das anotações.

\section{CONSIDERAÇõES GERAIS}

- Verificar o tipo de impresso utilizado na instituição e as normas para o seu preenchimento (onde anotar, cor da tinta, onde assinar). 
- Verificar se o cabeçalho do impresso está preenchido devidamente; caso não esteja, preenchê-lo ou completá-lo.

- Preceder toda anotação de horário e preencher a data na primeira anotação do dia.

- Anotar somente após tomar conhecimento do que foi anotado pelos plantões anteriores.

- Anotar informações completas, de forma objetiva, para evitar a possibilidade de dupla interpretação: não usar termos que dêem conotação de valor (bem, mal, muito, bastante, entre outros).

- Utilizar frases curtas c exprimir cada observação em uma frase.

- Anotar imediatamente após a prestação do cuidado, recebimento da informação ou observação de intercorrência.

- Nunca rasurar a anotação por ter essa valor legal; no caso de engano, usar "digo", entre vírgulas.

- Não utilizar o termo "o paciente" no início de cada frase, já que a folha de anotação é individual.

- Deixar claro na anotação se a observação foi feita pela pessoa que anota ou se é informação transmitida pelo paciente, familiar ou outro membro da equipe de saúde.

- Evitar o uso de abreviaturas que impeçam a compreensão do que foi anotado.

- Assinar imediatamente após o final da última frase e escrever a sigla da Escola: não deixar espaço entre a anotação e a assinatura.

Em relação às abreviaturas deve ser feita uma ressalva: as abreviaturas podem ser eventualmente utilizadas, desde que seu uso seja consagrado na instituição e na unidade de internação onde o estudante esteja estagiando. As abreviaturas que as autoras deste trabalho consideraram viáveis estão relacionadas em anexo.

\section{CONTEỦDO DAS ANOTAÇõES}

Do conteúdo das anotações deve constar:

- As condições gerais do paciente ao iniciar o plantão: estado mental e humor, condições físicas, sinais e sintomas, condições de drenos, sondas e catéteres, entre outras.

- Dados referentes às necessidades básicas:

- nutrição;

- hidratação; 
- sono e repouso;

- locomoção;

- motilidade;

- eliminações;

- cuidado corporal;

- regulação térmica e vascular;

- comunicação;

- recreação;

- integridade cutâneo-mucosa;

- oxigenação;

- terapêutica.

- Sinais e sintomas (objetivos e subjetivos).

- Acidentes e intercorrências.

- Recebimento de visitas, saídas e retornos (da unidade ou do hospital), alta, declaração de estado grave, óbito.

- As condições gerais do paciente ao terminar o plantão: devem dar uma idéia geral e completa de como o paciente passou durante o periodo e as condiçóes em que o estudante o deixou.

As necessidades básicas listadas foram selecionadas a partir dos trabalhos de HORTA (1975) e as anotações a elas referentes deveriam ser exigidas como informação mínima e essencial. As anotações a respeito de outras necessidades básicas deverão, obviamente, ser incluídas quando o paciente apresentar sinal ou sintoma de desequilíbrio no seu atendimento. Deverão ser anotadas, detalhadamente, as observações, informações e orientações referentes a cada necessidade básica. A título de exemplo, discriminam-se abaixo os itens a serem descritos para algumas delas. Assim:

- em nutrição anotar: aceitação ou não do alimento, razões de sua rejeição, tipo e quantidade de alimento consumido, formas de administração, jejuns, entre outros dados;

- em eliminações anotar: consistência e aspecto, cor, odor, volume, freqüência;

- em regulação térmica e vascular e oxigenação estão incluídos também as características do pulso e respiração, bem como o local de verificação dos sinais vitais;

- em terapêutica anotar: medicação, tipo, dose e quantidade (se necessário), via e local de administração, possíveis reações, substituições feitas, tratamentos executados e reações a eles: curativos, aspirações, drenagens, irrigações, lavagens, entre outros; 
Deve ser lembrado que disciplinas como Enfermagem Psiquiátrica, Administração em Enfermagem, Enfermagem Preventiva e Comunitária e Enfermagem em Centro-Cirúrgico adotarão critérios adicionais, tendo em vista as suas peculiaridades seja pelo tipo de assistência prestada, seja pela existência de impressos específicos para anotação de enfermagem.

A exigência no que tange à complexidade e à extensão das anotações variará de acordo com a evolução da capacidade de análise e síntese do estudante. Assim, se em Fundamentos de Enfermagem é exigida anotação minuciosa, em outras disciplinas poder-se-ão exigir anotações analíticas e concisas, com base nos itens relacionados neste roteiro.

FERNANDES, R. A. Q.; SALUM, M. J. L.; TEIXEIRA, M. B.; LEMMI, R. C. A.; MIURA, M. Nursing notes. Rev. Esc. Enf. USP, São Paulo, 15(1):63-68, 1981.

Aiming at some uniformity in nursing notes, the authors suggest a few norms on how to write them. This uniformity would help nursing students througout the whole nursing program.

\section{REFERENCIAS BIBLIOGRAFICAS}

ANGERAMI, E. L. S.; MENDES, J. A. C.; PEDRALzanI, J. C. Análise crítica das anotações de enfermagem. Rev. Bras. Enf., DF, 29(4): 28-37, 1276.

DUARTE, A. B.; REIS, J. E. M.; SANTOS, V. O. Importância das anotaçōes dos cuidados de enfermagem. Rev. Bras. Enf., DF, 29(6): 83-91, 1976.

HORTA, W. de A. Necessidades humanas básicas: consideraçōes gerais. Enf. Novas Dimens., 1(5): 266-8, 1975 .

OGUISSO, T. Os aspectos legais da anotação de enfermagem no prontuário do paciente. Rio de Ja. neiro, 1975. (Tese de Docência-Livre apresentada à Escola de Enfermagem Ana Néri da UFRJ).

RIBEIRO, C. de M. Auditoria de Serviços de Enfermagem. Rev. Bras. Enf., DF, 25(4): 91-103, jul./set. 1972. 


\section{ANEXO}

\section{ABREVIATURAS PERMITIDAS}

horas: $\mathrm{h}$

minutos: $\min$

membros inferiores: MMII

freqüência respiratória: $\mathbf{R}$

membros superiores: MMSS

pressão arterial: PA

pressão venosa central: PVC

soro fisiológico: $\mathrm{SF}$

soro glicosado: SG

membro inferior esquerdo: MIE

sonda nasogástrica: SNG

membro superior esquerdo: MSE

sala de operação: SO

membro superior direito: MSD

centro cirúrgico: $\mathrm{CC}$

membro inferior direito: MID

centro obstétrico: $\mathrm{CO}$

intra-muscular: IM

unidade de terapia intensiva: UTI

endo-venosa: EV

eletrocardiograma: ECG

via oral: Vo

eletroencefalograma: EEG

sub-cutânea: SC

tempo de sangria: TS

intra-dérmica: ID

tempo de coagulação: TC

temperatura: $\mathrm{T}$

hemoglobina: $\mathrm{Hb}$

pulso: $\mathbf{P}$

hematócrito: $\mathrm{Ht}$

elementos ou substâncias químicas: utilizar os símbolos convencionais $\left(\mathrm{O}_{2}, \mathrm{CO}_{2}, \mathrm{CaCO}_{3}\right.$, $\mathrm{KMnO}_{4}$ entre outros)

unidades de medidas: utilizar as siglas internacionais $(\mathrm{g}, \mathrm{mg}, \mathrm{ml}, \mathrm{mm}$, entre outras). 